\title{
分析化学(一)教学与科研互促的实践探索
}

谭亮 ${ }^{*}$, 陈超, 魏琳, 谭月明, 马铭

湖南师范大学化学化工学院, 长沙 410081

摘要: 分析化学 (一)是化学专业的专业核心课程之一。为提高课程教学质量, 提升学生学习兴趣, 实现教学与科研的 相互促进, 开展了科研成果融入教学内容、教学内容启发研究灵感等实践探索, 实施效果令人满意。

关键词: 分析化学(一); 科研成果; 教学内容; 相互促进

中图分类号: G642; O65

\section{Practical Exploration on Mutual Promotion between Teaching in Analytical Chemistry (I) and Scientific Research}

\author{
Liang Tan *, Chao Chen, Lin Wei, Yueming Tan, Ming Ma \\ College of Chemistry and Chemical Engineering, Hunan Normal University, Changsha 410081, China.
}

\begin{abstract}
Analytical chemistry $(\mathrm{I})$ is one of the core courses in chemistry major. We have performed the practical exploration, in which the scientific research achievements are integrated into the teaching contents and the latter are used to activate the research inspiration, in order to improve the teaching quality, enhance the students' interest in learning, and realize the mutual promotion between teaching and scientific research. The actual results are satisfactory.
\end{abstract}

Key Words: Analytical chemistry (I); Scientific research achievement; Teaching content; Mutual promotion

党的十九大以来, 我国高等教育进入内涵式发展新阶段。教育部陆续推出 “四新” 建设、“六卓 越一拔尖” 计划 2.0 、一流专业建设 “双万计划”、一流课程建设 “双万计划” 等一系列举措, 打响新 一轮全面振兴本科教育攻坚战 ${ }^{11]}$ 。2019年, 教育部印发 《关于深化本科教育教学改革 全面提高人才 培养质量的意见》, 推出 22 项措施深化本科教学改革, 落实学生忙起来、教师强起来、管理严起来、 效果实起来的系统部署。文件明确提出 “全面提高课程建设质量, 推动科研反哺教学”, 要求教师加 强课程体系整体设计, 提高课程建设规划性、系统性, 及时把最新科研成果转化为教学内容, 激发 学生专业学习兴趣 ${ }^{2}$ 。

分析化学是化学专业的专业核心课程之一。根据教学内容该课程一般分为分析化学(一)和分析 化学 (二) (或上、下)两部分, 分别讲授化学分析和仪器分析基本原理和基础知识 ${ }^{[3,4]}$ 。我校化学专业 分析化学课程目标包括: 1) 学生掌握分析化学基本理论、基础知识和计算方法, 了解常用仪器的构 造；2）能够根据分析任务选择合适的方法；3）形成发现问题、解决问题、研究问题的综合能力; 4) 具有严格的 “量” 的概念, 培养实事求是的科学态度、严谨务实的工作作风和良好的创新精神。 分析化学第一次变革催生了化学分析知识体系的建立, 第二、三次变革促成了仪器分析方法的涌现 和迅速发展。现代分析化学科学研究建立在各种灵敏、快速的仪器分析方法基础之上, 因此, 分析

收稿: 2021-04-06; 录用: 2021-04-26; 网络发表: 2021-05-06

“通讯作者, Email: liangtan@hunnu.edu.cn

基金资助: 湖南省普通高等学校课程思政建设研究项目(HNKCSZ-2020-0097) 
化学(二)教学与科研的相互促进得以实现, 一些研究成果相继推出 ${ }^{[5-8]}$ 。分析化学 $($ 一)的讲授内容多 为基础知识和经典理论, 通常认为与目前研究热点的关联程度不高, 教师将该课程的教学与科研有 机结合存在一定的难度, 学生容易产生 “知识过时” 或 “知识无用” 的误解。

\section{1 分析化学(一)教学与科研互促的可行性}

笔者所在的分析化学(一)课程教学团队由中青年教授、博士组成, 大部分教师承担该课程教学 多年, 教学经验丰富, 对课程目标和知识体系有较深刻的了解。教师的科学研究涉及电分析、光分 析和色谱分离分析等领域。因此, 实现课程教学与科研的相互促进具有良好的人员基础。

在高等教育课程教学中, 将科研成果融入/转化教学内容一直是培养学生科研思维和创新能力的 有效手段 ${ }^{[9,10]}$ 。另一方面, 一些教师在备课和教学过程中能够产生研究灵感 ${ }^{[11]}$, 教师通过教学可以 深入了解学科发展前沿及其动态, 有助于理清科研思路 ${ }^{[12]}$ 。分析化学(一)虽然主要讲授化学分析基 础知识, 但后者对于开展分析化学科学研究不可或缺。不少依托仪器分析的科研创新在局部工作中 涉及分析化学经典理论和基础知识(如平衡理论、误差和数据处理等), 这为开展教学与科研相互促 进的探索提供了条件。

\section{2 分析化学(一)教学与科研互促的实践探索}

教学团队秉承 “学生中心” 理念, 针对分析化学理论课和实验课开展了教学模式和教学方法改 革 ${ }^{[13,14]}$ 。为了实现分析化学 (一)教学与科研的相互促进, 教学团队进行了积极探索。

\section{1 科研成果融入教学内容}

笔者在分析化学(一)课程教学过程中精心挑选了一批分析化学科研论文作为教学素材和课外阅 读资料，其中以刊载教师本人科研成果的论文为主，赋予了该课程明显的特征。

在讲解 “酸碱缓冲溶液” 以及 “配位滴定滴定剂EDTA性质” 知识点时, 教师展示了三篇文献 ${ }^{[15-17]}$ 。 这些文献报导了笔者近年来在血管内皮细胞损伤标志物血栓调节蛋白 $(\mathrm{TM})$ 、血管性血友病因子 (vWF) 和内皮素-1 (ET-1)检测方面的研究工作, 涉及压电传感、电化学测量等不同的分析方法。教师 以 $\mathrm{pH}$ 7.4生理磷酸盐缓冲溶液(PBS)开场引入酸碱缓冲溶液的概念, 推导缓冲溶液 $\mathrm{pH}$ 计算公式后, 要 求学生讨论并设计一定体积 $0.1 \mathrm{~mol} \cdot \mathrm{L}^{-1} \mathrm{pH} 7.4 \mathrm{PBS}$ 配制的实验方案, 教师进行点评和总结, 让学生 知晓无论是在化学分析还是仪器分析中缓冲溶液都是最常用的试剂之一。在讲授EDTA性质时, 以 “细胞消化液中为何含有EDTA” 为题给学生布置课外阅读作业, 要求查阅相关科研文献撰写微报告, 丰富了平时考核的方式。上述实例的运用, 目的在于使学生了解基础知识的实际应用价值, 培养探 索精神, 也给学生传递了重要的理念：现代科学研究的基础是不同学科知识的交叉融合。

在讲解 “物质对光的选择性吸收” 知识点时, 教师选择报导荧光检测TM的文献 ${ }^{[18]}$ 。在该研究中, 笔者的研究小组分别合成了纳米金和抗体修饰纳米金并测量了两者分散液的紫外-可见吸收光谱。课 堂教学中, 教师首先展示了酒红色纳米金溶液和紫红色的抗体-纳米金复合物溶液的图片, 要求学生 基于互补色原理预测两者吸收峰的大致位置(500-560 nm), 之后教师展示实验测量的吸收曲线。随 后, 教师组织学生分组讨论为何抗体-纳米金复合物相对于纳米金其吸收峰位置会发生红移。通过预 测一验证-讨论-总结等一系列师生高效互动环节, 营造活跃的课堂氛围, 实现课堂教学由 “教师中心” 到 “学生中心” 的转变。

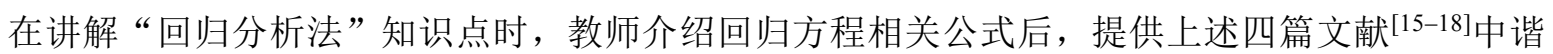
振频率变化值 $\left(\Delta f_{0}\right)$ 、荧光强度差值 $(\Delta F)$ 、电流强度差值 $(\Delta I)$ 和检测物 TM、vWF和ET-1的浓度 $c$ 等实验 数据, 要求学生现场计算截距、斜率以及相关系数, 确定一元线性回归方程, 并将利用 Excel/Origin/Sigmaplot等软件进行线性拟合作为课后作业布置。在教学中采用真实科研实验数据, 旨 在拉近低年级学生与科学研究的距离, 经典公式和计算机技术的先后使用有望加深学生对知识点的 掌握程度。 
为了考查科研成果融入教学内容对学习效果的影响, 笔者对73位同学发放了调查问卷, 收回有 效问卷72份, 调查结果见表1。

表1 科研成果融入教学内容对学习效果影响的调查结果

\begin{tabular}{cccc}
\hline \multirow{2}{*}{ 调查内容 } & \multicolumn{3}{c}{ 评价结果 } \\
\cline { 2 - 4 } & 同意 $/ \%$ & 基本同意 $/ \%$ & 不同意 $/ \%$ \\
\hline 能够加深对知识点的理解 & 83.3 & 11.1 & 5.6 \\
能够提升学习兴趣 & 88.9 & 6.9 & 4.2 \\
能够初步了解科学研究的方向和内容 & 87.5 & 9.7 & 2.8 \\
有助于培养创新精神 & 81.9 & 12.5 & 5.6 \\
讨论练习环节体现了 “学生中心” 理念 & 87.5 & 9.7 & 2.8 \\
希望在今后教学中加强科研成果的融入 & 95.8 & 2.8 & 1.4 \\
\hline
\end{tabular}

调查结果显示, 肯定 “能够加深对知识点的理解” 和 “有助于培养创新精神” 的学生比例超过 $94 \%$, 肯定 “能够提升学习兴趣” 的学生比例接近 $96 \%$, 肯定 “能够初步了解科学研究的方向和内容” 和 “讨论环节体现了 “学生中心’ 理念” 的学生比例超过 $97 \%$, 超过 $98 \%$ 的学生希望在今后教学中加 强科研成果的融入。这表明学生对科研成果融入教学内容的做法持积极肯定态度。

笔者基于平时成绩、期中成绩和期末成绩计算了近年来两个年级该课程的课程目标达成度, 结 果见图1。相对于2018级学生, 实施了科研成果融入教学内容改革的2019级学生的课程目标1、2和4 达成度均有一定程度提高, 特别是课程目标4 (具有严格的 “量” 的概念, 培养实事求是的科学态度、 严谨务实的工作作风和良好的创新精神)达成度由原先的低于预期值转变为略高于预期值, 证明上述 教学改革对学生创新精神的培养具有良好的促进作用。

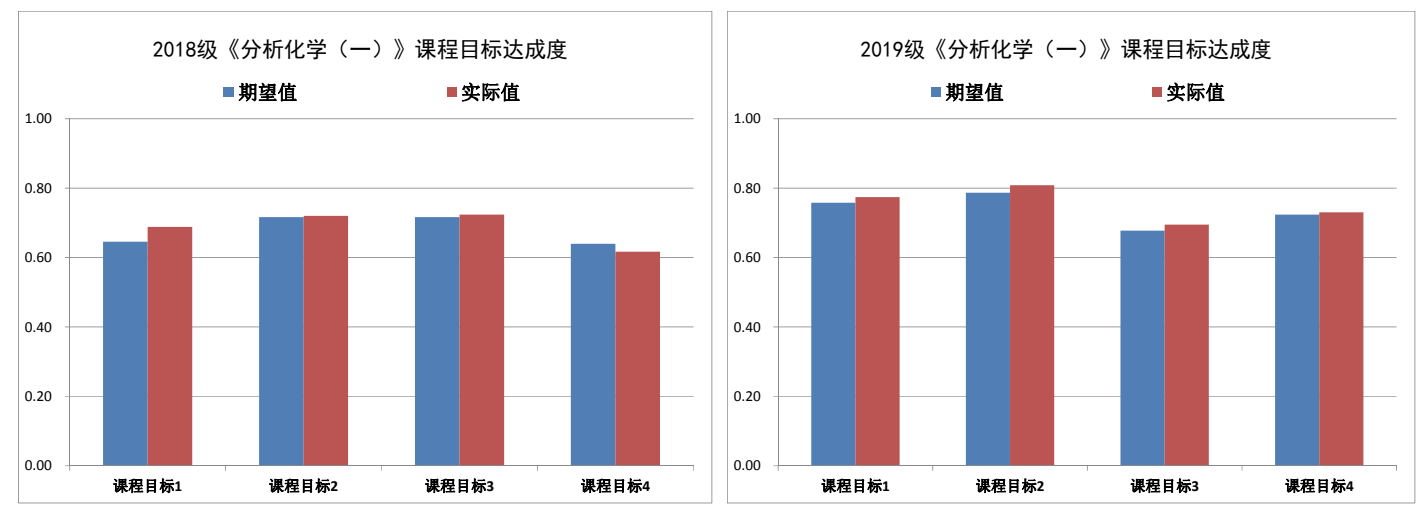

图12018级和2019级分析化学(一)课程目标达成度结果

电子版为彩图

\section{2 教学内容启发研究灵感}

笔者讲授分析化学(一)课程多年, 一直在思考教学内容能否为科学研究提供线索。近来笔者开 展了痕量重金属离子检测研究, “配位化合物稳定常数” 知识点为笔者提供了灵感, 为上述思考提 供了突破口。在基于Fenton型反应电化学检测 $\mathrm{Hg}^{2+}$ 的研究论文中, 制备了聚硫堇(PTH)和氨基化石墨 烯量子点(af-GQDs)共同修饰的玻碳电极, 基于配位化合物稳定常数的差异性, 利用 $\mathrm{Hg}^{2+}$ 破坏 $\mathrm{Cu}^{2+}$ 硫 脲络合物、夺取硫腿配体从而释放铜离子, 导致Fenton效应恢复, 实现了痕量 $\mathrm{Hg}^{2+}$ 的间接电化学检 测 ${ }^{[19]}$ 。在基于荧光检测的研究论文中, 合成了 af-GQDs荧光探针, 利用该荧光探针与 $\mathrm{Cu}^{2+}-\mathrm{PAN}$ 络合 
物之间较强的苂光共振能量转移导致的af-GQDs荧光猝灭, 开展了痕量铜离子检测, 基于EDTA破坏 $\mathrm{Cu}^{2+}$-PAN络合物导致的af-GQDs荧光恢复, 完成了EDTA的灵敏测量 ${ }^{[20]}$ 。这些研究工作继而被笔者作 为知识点应用实例用于分析化学(一)的教学, 启发学生的创新思维, 较好地实现了教学与科研的融 合。

\section{3 结语}

教师在分析化学(一)教学中将科研成果融入教学内容, 并根据教学内容产生了科学研究的灵感。 除了本文研究涉及的知识点外, 包括 “质量保证与质量控制” 和 “常用的分离富集方法” 等章节在 内的其他一些教学内容与分析化学科学研究有着密切的关系。教师将选择更多优秀的科研成果作为 知识点应用实例用于教学, 同时根据教学内容积极拓展科研思路。在 “学生中心、产出导向、持续 改进” 的课程建设理念指导下, 教学团队计划创建一批基于教学科研互促的教学案例, 努力打造一 流课程, 服务于新时代创新人才培养。

\section{参 考 文 献}

[1] 教育部. 全国普通高校本科教育教学质量报告(2018年度). 北京: 高等教育出版社, 2020.

[2] 教育部. 关于深化本科教育教学改革 全面提高人才培养质量的意见. [2019-10-08]. http://www.moe.gov.cn/srcsite/A08/s7056/201910/t20191011_402759.html

[3] 武汉大学. 分析化学(上册). 第6版. 北京: 高等教育出版社, 2016.

[4] 武汉大学. 分析化学(下册). 第6版. 北京: 高等教育出版社, 2018.

[5] 冯彩霞, 屈建芗, 李德亮. 广州化工, 2012, 40 (22), 159.

[6] 徐守芳, 陆宏志. 化学教育, 2014, 35 (2), 8.

[7] 王明齐. 科技创新导报, 2017, 14 (28), 229.

[8] 赵斌, 段宏基, 刘亚青, 张丛筠, 赵贵哲. 大学教育, 2020, No. 4, 173 .

[9] 陈贝贝, 何蔓, 胡斌. 大学化学, 2014, 29 (6), 11 .

[10] 余凡, 王亮, 李宝. 大学化学, 2020, 35 (8), 111.

[11] 王晶珊, 隋烟明, 乔利仙, 王爱华, 徐丽娟. 教育教学论坛, 2015, No. 36, 206.

[12] 袁建琴, 高斌战, 李丽, 张利环, 宋宝敏, 唐中伟, 宋芸, 李宏. 轻工科技, 2019, 35 (10), 159.

[13] 陈超, 邓文芳, 吴萃艳, 谭亮, 刘美玲, 方正法. 云南化工, 2020, 47 (1), 193.

[14] 谭亮, 陈超, 方正法, 马铭. 实验室科学, 2017, 20 (6), 235.

[15] Luo, Y.; Liu, T.; Zhu, J.; Kong, L.; Wang, W.; Tan, L. Anal. Chem. 2015, 87, 11277.

[16] Wang, W.; Ma, C.; Li, Y.; Liu, B.; Tan, L. Appl. Surf. Sci. 2018, $433,847$.

[17] Tian, B.; Zhao, L.; Li, R.; Zhai, T.; Zhang, N.; Duan, Z.; Tan, L. Anal. Chem. 2020, 92, 15916

[18] Kong, L.; Zhu, J.; Wang, W.; Jin, L.; Fu, Y.; Duan, B.; Tan, L. Spectrochim. Acta A 2017, 173, 675.

[19] Tian, B.; Kou, Y.; Jiang, X.; Lu, J.; Xue, Y.; Wang, M.; Tan, L. Microchim. Acta 2020, 187, 210.

[20] Jiang, X.; Kou, Y.; Lu, J.; Xue, Y.; Wang, M.; Tian, B.; Tan, L. J. Fluoresc. 2020, 30, 301. 